\title{
Challenging Beginning Teachers' Misconceptions of the Effects of Poverty on Educational Attainment in an Initial Teacher Education Programme in England.
}

\section{Ian Thompson, Associate Professor of Education, University of Oxford}

\section{Introduction}

Evidence from both empirical research studies and statistical analyses has repeatedly shown that the most economically disadvantaged students have the poorest educational outcomes in England Consecutive governments in the United Kingdom have expressed concerns over both 'social mobility' and the failure to educate the poor and most disadvantaged in society. However, the policy response in England, the only UK jurisdiction where education remains the concern of the central government, has been to combine a neoliberal policy of diversification in types of school and compensatory reforms aimed at disadvantaged students with a neo-conservative drive towards a more traditional curriculum and more rigorous testing (Burn \& Childs, 2016). At the same time, the government discourse that has often blamed schools and teachers and exhorted schools to do more without providing the necessary resources has only increased the pressure on disadvantaged children. Moves by the current government to supposedly increase social mobility through more selective state schools is likely to exacerbate inequality (Andrews, Hutchinson \& Johnes, 2016).

Yet there is also strong evidence that some new and established teachers either ignore or disbelieve evidence on the link between poverty and educational attainment (e.g. Smyth \& Wrigley, 2013; Thompson, McNicholl and Menter, 2015). Research also suggests that many teachers hold negative stereotypical views about impoverished young people that negatively affect students from vulnerable communities (e.g. Rank, Yoon \& Hirschl, 2003; Ridge, 2009). The challenge here is for initial teacher education (ITE) programmes to consider their role in overcoming social justice inequalities for disadvantaged students in schools (e.g. Cochran-Smith, 2004; Zeichner, 2009) through producing culturally and socially responsive teachers.

This chapter reports on two research projects within a well-established initial teacher education (ITE) partnership in England that explored the problematic issue of many beginning teachers' misconceptions of child poverty and educational attainment. A cultural historical activity theory (CHAT) analysis is used to consider the social situations of development in which beginning teachers learn and the complex interactions between the often competing object motives of different participants in ITE. The social situation of development is a CHAT concept originally used by Vygotsky (1998) to describe critical or important periods in childhood, as the learner encounters 
contradictions between their own psychological development and the demands of the learning situation, but also used by Edwards (2010) and others to describe social situations of adult learning and development such as learning to teach. The CHAT reference to object motive refers to the relevance or goal of an activity. The overall aim of the chapter is to contribute to this book's claim of reframing theoretically questions of educational inequality as well as to consider ways in which beginning teachers might reframe their thinking about pupils living in poverty. The chapter argues that confronting deficit models of poverty requires a form of practical theorising (McIntyre, 1993) which involves subjecting theory to critical examination. Although practical theorising is not a CHAT concept, its dialectical focus makes it a helpful complementary approach.

\section{Poverty Preconceptions and Pressures of Performativity}

Popular stereotypes of people living in poverty affect both preconceptions of individuals and policy (Buras, 2014; Gorski, 2012). The resultant deficit model, which directs blame onto perceived shortcomings of the poor rather than on structural inequalities in the educational system, can lead to stereotypical views about students and their families. Views that essentially pathologise the poor (Dudley-Marling \& Lucas, 2009) are widely accepted by both teachers and teacher educators (Ullucci \& Howard, 2015). False assumptions of low educational aspirations of impoverished families can also perpetuate inequality (Cummings et al., 2012). Reviews of the teacher education literature provide strong evidence that pre-service teachers' pre-existing beliefs shape their initial teacher education experience and that these views are remarkably resistant to change (e.g. Richardson, 2003).

Of course being resistant to change does not mean impossible to change. Some research suggests that ITE programme can challenge some entrenched views through a combination of exposure to relevant theory through reading relevant research and policy literature and small scale research projects in placement schools (e.g. Ellis, Thompson, McNicholl \& Thomson, 2016). However, whilst much research has focused on the relationship between poverty and educational achievement, far less has addressed the impact of pressures of performativity on teachers' understanding, perspectives, and enactment of teaching for social justice. It is misleading to simply blame teachers for the issue of poverty and educational achievement without understanding the systemic issues that lead to or exacerbate these views. Arguably, virtually all teachers come into the profession wanting to make a difference to the lives of the young people they will teach. These teachers are normally committed to improving the learning opportunities for all the young people in their care and most undertake ITE programmes that espouse issues of social justice. 
So where does this disconnect between the evidence base and some teachers' negative perceptions of disadvantaged students come from? One probable reason is the constant pressure on teachers in England to perform. League tables based on published examination results and the threat of imminent school inspection often dominates the discourse and pedagogic practice of schools and teachers. Indeed one of the inevitable consequences of high stakes testing in schools designed to hold schools and teachers accountable (Ball, 2006; Furlong \& Lunt, 2014) is a restriction of the curriculum for disadvantaged children. Pressures on schools and teachers to introduce measures for their students to pass the next test can result in the abandonment of strategies that assist young people's long-term cognitive development or emotional wellbeing. Beginning teachers are not immune to these pressures as their experience of working with students living in poverty is mediated both by their mentor's perspectives and by other teachers' views as well as the pressures of performativity within the school itself. This suggests the importance of the additional mediation of the university tutor in providing questions or alternative perspectives.

Another reason for the disconnection between beginning teachers' intentions to support impoverished learners and their acceptance of deficit views may be that many lack personal knowledge and understanding of the effects of poverty. Teachers come into the profession as a result of academic success and manyhave come from relatively stable economic backgrounds. This lack of personal experience of poverty is compounded for some teachers by a lack of teaching opportunities in urban schools during their ITE programme. Again the mediating role of the university assumes great importance here.

However, even personal experience of poverty or of teaching children living in poverty may not be enough to develop an awareness of the implications for pedagogy and curriculum design. Indeed the implication that teachers can only learn about the lives of children living in poverty from direct experience has partly fuelled the rise of employment based routes such as Teach for America and Teach First in England. However, the apprenticeship models of these and other routes, with a decreased higher education influence and an emphasis on teaching as a craft to be acquired in situ, stands in stark contrast to the practical theorising approach of clinical practice model of the Oxford Internship (see Hagger \& McIntyre, 2006). This clinical practice approach stresses both the dialectical interplay between theories of education and teaching practice as well as the developmental importance of disrupting and questioning previous assumptions about pedagogy and the ways particular people learn in particular circumstances. 


\section{A Cultural Historical Activity Theory Research Approach}

In order to understand the implications of practical theorising for changing beginning teachers' views through reframing their thinking it is helpful to look at some key CHAT concepts that might inform understandings of beginning teachers' development (see Edwards, 2010 for an extended discussion). A cultural historical activity research focus in ITE is simultaneously on the constant dialectical interplay between:

- the macro element of the policies and practices of teacher education;

- the meso element of historically and culturally defined practices within institutions;

- and the micro element of individual behaviour and action.

Beginning teachers face multi-layered social situations of development that involve a complex interplay between individual, social and institutional histories and the sometimes conflicting object motives of the actors involved. These social situations, Edwards (2010) argues, include learning about relatively stable practices such as a school curriculum, but also situations where practices are less well defined such as understanding the learning of children living in poverty and adjusting pedagogy accordingly. The latter situations might involve a more critical or questioning stance. The argument advanced in brief here is that these less well defined practices can produce useful social situations of development for beginning teachers as they negotiate through the process of practical theorising both the national contexts of teacher training and the particular experiences of their school and university contexts.

\section{Research on Challenging Misconceptions}

Two recent examples of research conducted over a period of four years in a well established ITE programme in Oxford illustrate both the difficulties and possibilities for challenging and potentially changing entrenched views. Common concerns of these two research studies were issues of how beginning teachers understand the effect of poverty on students' educational achievement, and what they as prospective teachers can do to effect change. The Internship Scheme, as the Oxford ITE programme is known (Benton, 1990), is a partnership with state schools most of which are located in the city of Oxford and the county of Oxfordshire. Oxford is a small city in the south-east of England with unemployment rates well below the national average. However, house prices in the city are significantly above the national average partly because of the proximity of London, but there are parts of the city with particularly acute levels of deprivation. After adjusting for housing costs, $25 \%$ of the city's children live in poverty. Oxfordshire, in contrast, is relatively wealthy but each urban and rural setting has pockets of significant poverty. 
The first study, Student Teachers' Perceptions of Poverty (Study One), illustrates the problematic issue of some beginning teachers' perceptions of poverty, whilst the second, Preparing Beginning Teachers to Understand and Work Effectively with Young People Living in Poverty (Study Two), suggests the potential power of a focused intervention to provoke a confrontation in thinking through creating a social situation of development. Study One investigated ways that secondary beginning teachers' views on poverty were subjected to challenge and change during their course whilst Study Two was a more focused project involving beginning teachers engaging in small scale research in their placement schools. The method and findings as well as policy and practice implications of these research studies has been documented in full elsewhere (Burn et al.; Ellis et al., 2016; Thompson et al., 2016). Here the focus is on the implications of the findings from these studies for challenging misconceptions of the effects of poverty.

Study One was a mixed methods study that highlighted some of the difficulties faced by teacher educators in challenging entrenched views on poverty and educational attainment. The two key research questions were:

1. How do programmes of ITE frame and seek to address the link between poverty and poorer educational outcomes?

2. To what extent do student teachers' understandings of and attitudes towards poverty change or develop during their programme of study?

The methods involved: pre and post course surveys that examined the beginning teachers' beliefs and attitudes to poverty and educational attainment; course provocations; and focus group interviews. The project involved a series of provocations early on in the course such as course research readings and a whole cohort lecture on issues of poverty and educational achievement. The second stage of the research involved a second survey and focus group interviews at the end of the course to gauge the extent that views were changed.

In the first survey, $82 \%$ of the cohort $(n=185)$ described themselves as located in middle to high income backgrounds. When asked what they believed had the largest impact on students' educational outcomes the results were: Parents'/Carers' Attitudes to Education 81\%; Social Class 8\%; Income Levels $7 \%$; gender $3 \%$. The vast majority seemed to hold deficit views about children in poverty by 
blaming attitudes rather than economic and social conditions. In the second survey ( $n=166)$, conducted at the end of the course, $24 \%$ disagreed with the assertion that there was a link between poverty and students' educational outcomes. This was a surprising and worrying finding for a course that had repeatedly made this link explicit through the sharing of research findings in University and school-based sessions. It can also be argued that the majority of the $76 \%$ of the trainees who accepted the link between poverty and educational attainment fell back on deficit models for their interpretation of why this should be the case. 118 comments on the reasons for the link were coded for 4 different factors: parental deficit (41\%); pupil deficit (19.5\%); school factors (positive and negative) $(7.5 \%)$; and socio-economic factors $(32 \%)$.

Study Two used the introduction of the Pupil Premium Grant (PPG) for publicly funded schools in England aimed at raising the attainment of disadvantaged pupils as a research stimulus to ensure that trainee teachers understood the nature of poverty. The PPG is additional government funding to schools for disadvantaged pupils where eligibility for free school meals is the main measure of deprivation. The intervention, jointly designed by the university and its partnership schools, required all student-teachers to undertake a small-scale collaborative research project investigating the use of PPG funding within their second placement school in any way that they and the school's professional tutor (the teacher responsible for co-ordinating their school learning) chose. For example, some groups explored the impact of the PPG spending in school on the PPG pupils by exploring the stated aims of school interventiosn with the percpetiosn of the pupils affected. In most cases this involved direct contact with PPG students through interviews of focus groups. The research was to be presented to the senior management of the school who were responsible for justifying their expenditure to central government.

The mixed-methods research design explored both the professional tutors' perspectives and choices about the project within their distinctive school settings as well as the beginning teachers' thoughts about their experiences within those particular contexts. The methods of data collection had been trialled the previous year when the project was implemented as a pilot study in a number of partnership schools. Detailed case studies were conducted within six partnership schools, three in large urban areas and three in predominantly rural areas. Each involved an interview with the professional tutor, observation of the beginning teachers' presentations in school, and individual interviews with three of the beginning teachers. 
Evaluation data across the whole partnership suggested that the projects operated successfully in most cases with the student-teachers encouraged to ask critical questions about current practices intended to support the learning of young people living in poverty, and to relate those practices to other sources of evidence. The questionnaire data indicated that over $90 \%$ of respondents $(n=140)$ had the opportunity to carry out the PPG investigation in their second placement school. The majority (74\%) regarded it as a valuable learning experience that had enabled them to develop a better understanding of both the PPG and the government policy underpinning it, as well as of the ways in which their individual schools were using the funding and any difficulties associated with it. The final element of the research was a series of questions asked of all the beginning teachers involved in the research projects about their experience of the investigation and their perceptions of its value.

The case-studies revealed considerable variation in the nature of the projects undertaken by the student-teachers and in their complex social situations of development. However, both the individual cases and the whole-course evaluation data suggest that the project was effectively implemented in the vast majority of schools, enabling the students-teachers to engage with issues of poverty and its relationship to young people's educational experiences and outcomes. Direct experience of talking to children in poverty, and of evaluating PPG spending allowed them to better understand the constraints to learning experienced by these young people. However, some beginning teachers were critical of their schools' defensive reactions to the research and the fact that $10 \%$ of the student-teachers were not given the opportunity to carry out an investigation hints at the range of constraints and challenges for this sort of research.

\section{Discussion and Conclusions}

Study One suggested that whilst ITE courses can challenge some preconceptions some entrenched views are difficult to change. The majority of the student-teachers held deficit models at the start and end of the course and even those that accepted the correlation between poverty and educational outcomes essentially blamed the parents or a lack of imagination or ambition within the child. Simply being told that this was not true had very little impact and a significant minority did not accept the link at all between poverty and educational achievement. If beginning teachers hold entrenched deficit models that essentially blame the learner then a disruption or dislocation through a social situation of development may be required to change these seemingly entrenched views. The findings of Study Two suggest that direct experience of researching with young learners from impoverished 
backgrounds, backed up by reflections on literature and findings from other research studies, can dislocate and challenge previous assumptions.

A second consideration is the need to analyse the complex relationship between individual learning and the social situations of development in which that learning occurs. Thus in Study Two the research task was the deliberate introduction of a stimulus designed to mediate the experience for the beginning teachers of teaching disadvantaged students. In this form of practical theorising, the experience of research was mediated both through presenting the findings to other staff in the school and the subsequent discussion of the learning observed. This was so for both initial teachers in schools with high concentrations of disadvantaged students and those where the issue was largely hidden. The first intervention did not necessarily create an effective social situation of development as it focused largely on individual cognition which was heavily dependent on both school context and the quality of school mentor and other teacher mediation. The second intervention in creating a social situation of development around research was more likely to allow the recontextualisation of knowledge for the beginning teachers.

What the findings from these studies make clear is that successfully challenging beginning teachers' understandings of social justice and equity in education is not just about direct experience of working with children living in poverty. Simply relying on placement experiences, and strong, well established courses with social justice as a core value may not in itself be enough to change longestablished patterns of belief. Change also requires input from literature, research provocations, and collaborative challenge developed in social situations of development. The practice-based meanings developed in understanding the use of the PPG through research was effective precisely because they were open to scrutiny, critique and recontextualisation though the process of practical theorising. The participants in the project were actively involved in the interpretation of the complexities of poverty and education rather than being told what to think by school or university mentors. These findings offer hope that creating social situations of development around disadvantage can encourage beginning teachers to learn to use, question and develop different kinds of evidence and different ways of thinking. Through this process of practical theorising they can develop new understandings of their role in making schooling more equitable for children living in poverty.

The research reported here also reaffirms the importance of designing interventions that take account of the different object motives that student-teachers encounter in school/university partnerships. Student-teachers are engaged in a multi-layered social situation of development within the specific social and cultural contexts of both their placement schools and their university environment. From a CHAT perspective, the findings reported here suggest that if ITE programmes are to engage 
meaningfully with wider issues of social justice and reframe beginning teachers' thoughts about poverty and learning, then more attention needs to be paid within such programmes to the conflicting object motives of professional tutors, beginning teachers, and mentors and to the mediating role of individual, social and institutional histories and experiences. The findings also confirm that in social situations of development of educational complexity, such as working with students living in poverty, contextualised intervention may be needed to disrupt previously held professional assumptions and positions.

\section{References}

Andrews, J., Hutchinson, J. and Johnes, R. (2016) Grammar Schools and Social Mobility. London: Education Policy Institute.

Ball, S. J. (2006) Education policy and social class: The selected works of Stephen J Ball. London: Routledge.

Benton, P. (ed.) (1990) The Oxford Internship Scheme. London: Calouste Gulbenkian Foundation. Buras, K. L. (2014) There Really Is a Culture of Poverty: Notes on Black Working-Class Struggles for Equity and Education. In P. C. Gorski and J. Landsman (eds.), The Poverty and Education Reader: A Call for Equity in Many Voices (pp.60-75). Sterling, VA: Stylus Publishing LLC.

Burn, K. and Childs, A. (2016) Responding to poverty through education and teacher education initiatives: a critical evaluation of key trends in government policy in England 1997-2015. Journal of Education for Teaching, 42:4: 387-403.

Burn, K., Mutton, T., Thompson, I., Ingram, J., McNicholl, J., Firth, R. (2016) The impact of adopting a research orientation towards use of the Pupil Premium Grant in preparing beginning teachers in England to understand and work effectively with young people living in poverty. Journal of Education for Teaching, 42(4): 434-450.

Cochran-Smith, M. (2004) Walking the Road: Race, diversity and social justice in teacher education. New York: Teachers' College Press.

Cummings, C., Laing, K., Law, J., McLaughlin, J., Papps, Todd, L. and Woolner, P. (2012) Can changing aspirations and attitudes impact on educational attainment? A review of interventions. York: Joseph Rowntree Foundation.

Dudley-Marling, C. and Lucas, K. (2009). Pathologizing the language and culture of poor children. Language Arts, 86(5): 362-370. 
Edwards, A. (2010) How can Vygotsky and his legacy help us to understand and develop teacher education? In V. Ellis, A. Edwards, and P. Smagorinsky (eds.) Cultural-historical Perspectives on Teacher Education and Teacher Development. London: Routledge, pp. 63-77.

Ellis, S., Thompson, I., McNicholl, J. and Thomson, J. (2016) Student Teachers' Perceptions of the Effects of Poverty on Learners' Educational Attainment and Well-being: Perspectives from England and Scotland. Journal of Education for Teaching, 42(4): 483-499.

Furlong, J. and Lunt, I. (2014) Inequality and Education: continuing the debate. Oxford Review of Education, 40:6, 667-679.

Gorski, P. C. (2012) Perceiving the problem of poverty and schooling: Deconstructing the class stereotypes that mis-shape education practice and policy. Equity \& Excellence in Education, 45.2: 302-319.

Hagger, H. and McIntyre, D. (2006). Learning Teaching from Teachers: Realizing the Potential of School Based Teacher Education. Maidenhead: Open University Press.

McIntyre, D. (1993). Theory, Theorizing and Reflection in Initial Teacher Education. In J. Calderhead \& P. Gates (Eds.), Conceptualising Reflection in Teacher Development (pp. 39-52). London: Falmer.

Rank, M. R., Yoon, H.-S. and Hirschl, T. A. (2003). American poverty as a structural failing: Evidence and arguments. Journal of Sociology and Social Welfare, 30(4): 3-29.

Richardson, V. (2003) Preservice Teachers' Beliefs. In J. Raths and A.C. McAninch (eds.) Teacher Beliefs and Classroom Performance. Greenwich, CT: Information Age Publishing, pp 1-22.

Ridge, T. (2009) Living with Poverty: A review of the literature on children's and families' experiences of poverty, (Research Report No. 594). Norwich: Department for Work and Pensions.

Smyth, J. and Wrigley, T. (2013) Living on the Edge: Rethinking poverty, class and schooling. New York: Peter Lang.

Thompson, I., McNicholl, J. and Menter, I. (2016) Student Teachers' Perceptions of Poverty and Educational Achievement. Oxford Review of Education, 42(2): 214-229.

Ullucci, K. and Howard, T. (2015) Pathologizing the poor: implications for preparing teachers to work in high-poverty schools. Urban Education 50 (2): 170-193.

Vygotsky, L.S. 1998. The Collected Works of L.S. Vygotsky. Vol. 5. Child Psychology. New York: Plenum. 
Zeichner, K. (2009) Teacher Education and the Struggle for Social Justice. New York and London: Routledge. 